Sharif University of Technology
Scientia Iranica
SCIENTIA
I RAN ICA
http://scientiairanica.sharif.edu

\title{
On the measurement of transverse shear stress in a rectangular open channel using an optimal Preston tube
}

\author{
B. Lashkar-Ara* and M. Fatahi \\ Department of Civil Engineering, Jundi-Shapur University of Technology, Dezful, Iran.
}

Received 29 March 2017; received in revised form 14 January 2018; accepted 24 February 2018

\section{KEYWORDS}

Shear stress;

Preston tube;

Differential pressure;

Transducer;

Aspect ratio.

\begin{abstract}
The laboratory studies have been carried out in this research. After determining the sensitivity analysis of the Preston tube diameter in shear stress, four Preston tubes with external diameters of $3.2,3.9,4.7$, and $6.3 \mathrm{~mm}$ were used. The aspect ratios of 2.86 to 13.95 were examined. For measuring the pressure difference of the Preston tube, a 200 millibar differential pressure transducer with 0.01 accuracy of the original scale was used. Laboratory results demonstrated that Preston tubes with a diameter of $3.9 \mathrm{~mm}$ presented the minimum difference in the average value of the shear stress resulting from the Bechert and Patel calibration equations. Therefore, by using the Preston tube with an optimal diameter, transverse distribution of shear stress in channel beds and walls was determined. The outcome of this part of the study is two dimensionless relationships for determining the local shear stress both on the bed and wall. These relationships are a function of aspect ratio $B / H$ and the bed relative coordinates $b / B$ in cross-section and $Z / H$ sidewall. The survey showed that the dimensionless bed shear stress distribution was considerably influenced by the aspect ratio. The transverse distribution of wall shear stress was independent of the aspect ratio for $B / H>3$.
\end{abstract}

(C) 2020 Sharif University of Technology. All rights reserved.

\section{Introduction}

In uniform flows, the friction force is always equal to that effective component of gravity force, which is in the direction of the fluid flow. The frictional force per wetted perimeter unit in a channel is called shear stress. It is plausible that the transverse distribution of shear stress in wide and broad channels is not uniform. Determination of the boundary shear stress and its distribution along the wetted perimeter is a fundamental issue in open-channel flow. Shear stress distribution is primarily affected by the secondary flows, sediment transport rate, erosion or sedimentation, and geometry

\footnotetext{
*. Corresponding author.

E-mail address: Lashkarara@jsu.ac.ir (B. Lashkar-Ara)
}

doi: $10.24200 /$ sci. 2018.20209 of the channels. The shear stress distribution and flow resistance in both simple and compound channels with smooth and rough surfaces have been studied by many researchers.

Olsen and Florey [1] studied trapezoidal, rectangular, and triangular sections using finite difference methods and analytical approaches. It was shown that the distribution of frictional force varied depending on the cross-section shape; however, the cross-section size in terms of the frictional force distribution was noneffective. The aforementioned results also showed that the bed maximum frictional force was close to the theoretical stress amount resulting from the channel slope, while this force in channel walls was limited to about 0.76 of $\gamma H S$.

Using a three-point suspension system method, Ghosh and Roy [2] directly measured the shear stress in rectangular and trapezoidal open channels with 
smooth and rough beds. Their results showed that shear stress distribution around the wetted perimeter was non-uniform.

Kartha and Leutheusser [3] conducted a series of experiments to determine of the shear stress distribution in order to design stable alluvial channels by tensile forces. Experiments were performed in a rectangular laboratory flume with a smooth wall in aspect ratios between 1 and 12.5. They measured shear stress by Preston tube. For calibration of Preston tube, the indirect method was applied, and the law of the wall and velocity logarithmic distribution was used. At that time, they indicated that none of the analytical available techniques could calculate the shear stress for a proper design of alluvial channels.

Knight and Patel [4,5] performed a number of experiments to calculate the shear stress distribution in a rectangular channel with a smooth bed in aspect ratios of 1 to 10 . They found that the number and shape of the secondary flow cells had a different distribution in different aspect ratios. In this study, multiple pairs of clockwise or anti-clockwise secondary flow cells were observed. They also reported maximum and average shear stress in different aspect ratios. The interaction between secondary flows and shear stress distribution is shown in Figure 1.

Knight et al. [6] carried out experiments on channels with homogenous and heterogeneous roughness and presented equations to determine the average and maximum shear stresses in the bed and wall. These equations are presented as a fraction of the total shear force and include aspect ratio, walls slope, and relative roughness. They found that the percentage of the wall shear force would be reduced by increasing $P_{b} / P_{w}$ and $K_{s b} / K_{s w}$.

Sensitivity analysis of Preston tube diameter by Sutardi and Ching [7] showed that when the ratio of Preston tube diameter to boundary layer thickness is 0.048 and the pressure gradient is zero, the pipe with a $3.23 \mathrm{~mm}$ diameter has the least difference in determining the flow resistance factor calculated by the equations presented by Bechert [8] and Patel [9].

Ardiçlioğlu et al. [10] conducted an experimental study for the shear stress distribution throughout the

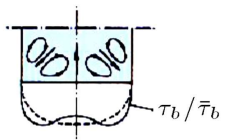

$B / H=1$

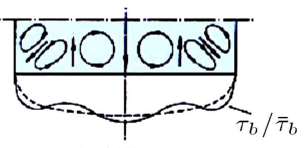

$B / H=2$
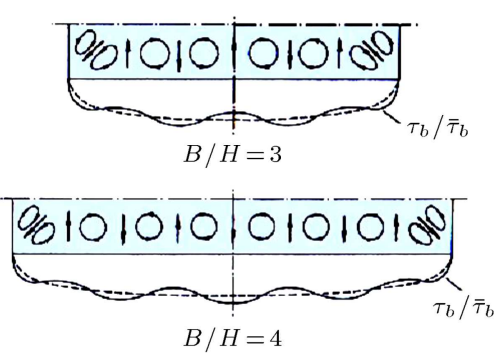

Figure 1. Interaction between secondary flow cells and shear stress distribution in different aspect ratios $[4,5]$. entire length of the cross-section in a fully developed boundary layer area, in an open rectangular channel, in both smooth and rough surfaces. By measuring the speed in both smooth and rough surfaces, they conducted 48 tests. By using the logarithmic distribution of velocity, the average shear stress in the crosssection for aspect ratios of 4.2 to 21.6 and the Froude numbers of 0.12 to 1.23 was measured. The results for smooth and rough surfaces are shown respectively in the following relations.

Smooth surface:

$$
\tau_{m}=-0.043-0.053 b / h+2.06 \mathrm{Fr},
$$

Rough surface:

$$
\tau_{m}=-0.019-0.013 b / h+5.86 \mathrm{Fr} .
$$

Their study led to the introduction of a secondorder polynomial for the determination of the shear stress distribution along the cross-section.

$$
\frac{\tau_{0}}{\tau_{m}}=0.247(2 y / b)^{2}+0.007(2 y / b)+1.079,
$$

where $\tau_{0}$ is the total shear stress, and $\tau_{m}$ is the local shear stress.

Using a method called SKM, Knight et al. [11] presented a simple model to predict the depth-averaged velocity and shear stress in trapezoidal channels under the presence of the secondary flow. An extensive range of shear stress data was used for validating the model. Results showed that the transverse velocity derived from this approach was consistent with field observations, while the adjustment for boundary shear stress does not always exist.

Lashkar-Ara et al. [12] used the Preston tube and utilized the indirect method to measure the average local shear stress in bed and wall of smooth rectangular channels. Lashkar-Ara and Fathi-Moghadam [13] directly measured the shear stress in smooth rectangular channels and introduced a so-called knife edge flume method. The flume was equipped by load cells in such a way that has the ability to measure the total shear force exerted on the wetted perimeter. For the separation of bed and wall shear stress position, the Preston tube with an outer diameter of $4 \mathrm{~mm}$ was used. To convert the static and dynamic pressure difference recorded in the Preston tube to the shear stress, the Patel calibration curve was used. The results of their research showed that direct and indirect methods of shear stress management had 4 and $8 \%$ errors, respectively, in comparison with theoretical equations.

Haifeng et al. [14] designed a micro floating element shear stress sensor.

This micro-fabricated floating element sensor was developed to measure the shear stress in laminar 
flow channels. The sensor with dimensions of $4 \times$ $3 \times 0.5 \mathrm{~mm}^{3}$ was fabricated by Inductively Coupled Plasma (ICP) etching techniques with a single mask. They designed a three-layer packaging strategy to reduce parasitic capacitance and realized flush mounting with the wall. Their experiments showed that this prototype sensor could measure shear stress at least $35 \mathrm{~Pa}$ with a sensitivity rate of $27 \mathrm{mv} / \mathrm{Pa}$. The linearity was measured $3.4 \%$, while the repeatability was $4.9 \%$.

Devi and Khatua [15] predicted depth-averaged velocity and the boundary shear stress distribution of a compound channel based on the mixing layer theory. Their analytical solution was obtained by the Shiono and Knight Method (SKM), considering a new panel of shear layer width at the junction. They conducted a reliable experimental measurement for quantification of the shear layer width and provided new calibrating coefficients for secondary flow and friction factor. The model was found to provide satisfactory results when applied to experiments, the UK Flood Channel Facility (FCF) and the datasets of natural rivers.

Park et al. [16] directly measured the bottom shear stress under high-velocity flow conditions to achieve high-velocity flow conditions; a laboratoryscale flume has been specially made in which flow velocity can reach $3 \mathrm{~ms}^{-1}$. In addition, an instrument that can directly measure the bottom shear stress was developed and validated. The newly built flume can achieve the Reynolds number that is comparable to that in flooding rivers when it is based on the local water depth near the revetment blocks.

Shan et al. [17] used a simple method to estimate the bed shear stress in smooth and vegetated compound channels based on the Darcy-Weisbach equation. This method contains a dimensionless parameter $A_{i}$ to represent the relationship between the bed shear stress and the velocity close to the channel bed $\left(U_{b}\right)$, which is determined in each divided domain. This method is verified in two smooth compound channels with different geometries and in one compound channel with emergent floodplain vegetation. The comparison between predicted and measured bed shear stresses indicates the good predictive capability of this method, particularly in the mixing region.

Sheikh Khozani and Bonakdari [18] used five different methods to estimate the shear stress distribution in compound channels. The methods proposed by Yang and Lim (YLM) [19], Khodashenas and Paquier (KPM) [20], Sterling and Knight (SKM) [21], Zarrati et al. (ZAM) [22], and Bonakdari et al. (BAM) [23] are compared with experimental data. They concluded that ZAM showed more accurate results than BAM; however, BAM required solving much fewer equations than ZAM and presented more accurate results than other geometric methods. Among all models, BAM is proposed as a simple and accurate model for predicting the shear stress distribution in compound channels.

Mohammadi [24] conducted several measurements to explore the hydraulic characteristics of a V-shaped bottom channel. He used a propeller for point-wise velocity measurements. According to the results, the lateral variations of depth-averaged velocities indicate that the velocity distributions were almost symmetrical about the cross-sectional centerline, except for some flow cases, in which there were slight deviations, despite the fact that the flow condition was uniform for all cases. In addition, it was found that the widely used log-law for the vertical profile of velocity did not appropriately model the velocity distribution in this particular channel shape. Considering the results obtained for the span- and depth-wise velocity distributions, especially the distortion of the isovels and the location of maximum velocity, there is strong evidence of secondary currents that are present in this channel cross-section.

Previous studies have shown that various parameters, such as aspect ratio, roughness, secondary flow, and eddy viscosity, affect the transverse distribution of shear stress. The aim of this study can be considered from two perspectives. Firstly, according to previous studies, the local shear stress resulting from the Preston tube is sensitive to its pipe diameter. Secondly, aspect ratio is effective in the number of secondary flow cells. The simultaneous effect of both of these two parameters on the transverse distribution of wall shear stress has not been discussed yet in previous studies. Therefore, to present the governing equation of the shear stress in the bed and wall of flat rectangular channels, this experimental research aims to study the transverse distribution of shear stress based on sensitivity analysis of the Preston tube diameter.

\section{Methodology}

In this research, a $10 \mathrm{~m}$ length flume with $60 \mathrm{~cm}$ width and $70 \mathrm{~cm}$ height is used in the hydraulic model and a river engineering laboratory of Jundi-Shapur University of Technology, Dezful, Iran to determine the transverse distribution of shear stress based on the sensitivity analysis of the Preston diameter. To this end, four Preston tubes with external diameters of $3.2 \mathrm{~mm}, 3.9 \mathrm{~mm}, 4.7 \mathrm{~mm}$, and $6.3 \mathrm{~mm}$ were used to determine the local shear stress in the channel bed. By assuring the development of the boundary layer, eleven measurement stations were installed, each $30 \mathrm{~cm}$ into the flume. The location of the stations and the schematic of the experimental system are illustrated in Figure 2 .

By using the momentum integral equation for the flow in a zero-pressure gradient and concerning Prandtl's one-seventh power law for modeling the 


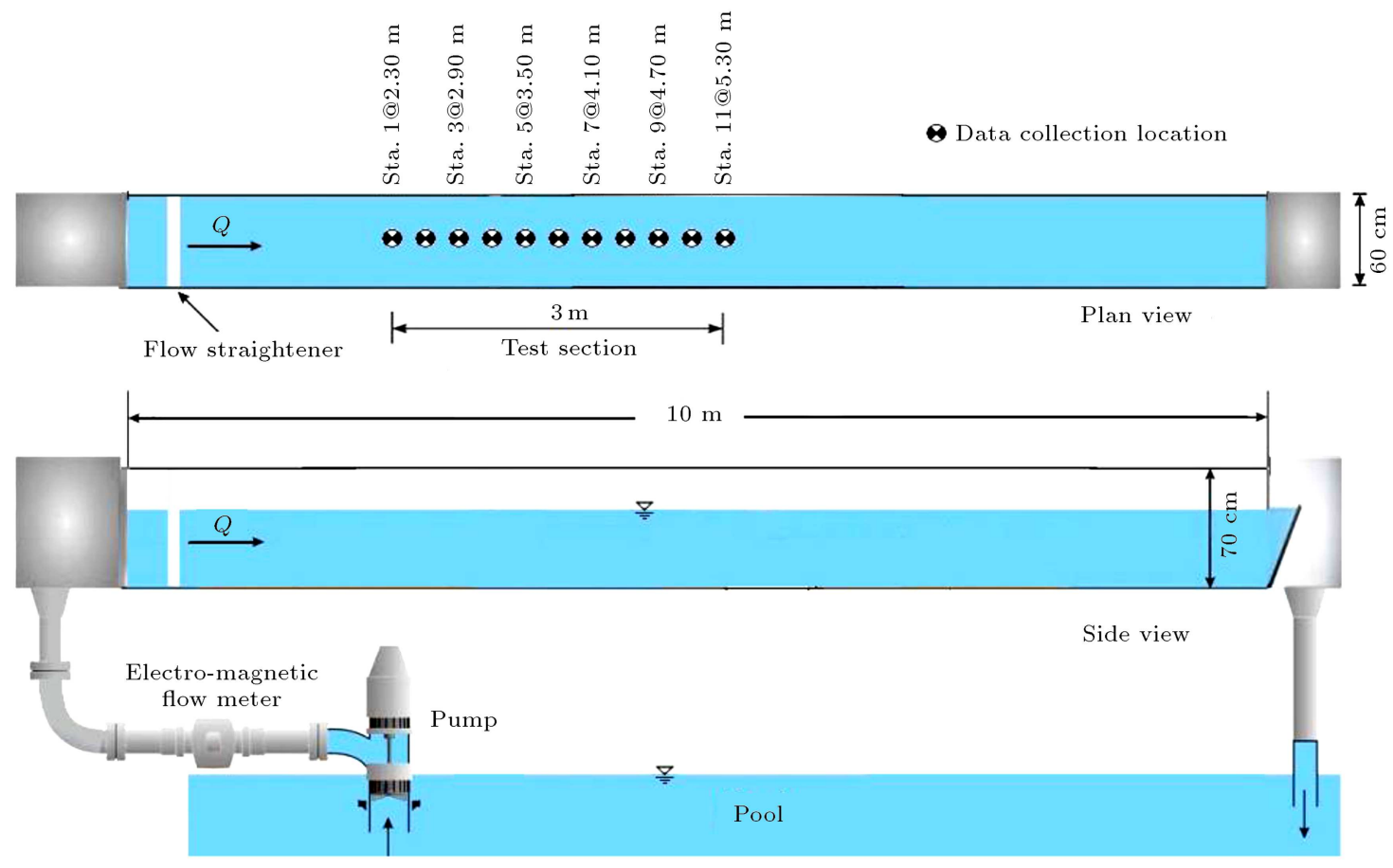

Figure 2. Experiment's schematic.

velocity index in turbulent flow on smooth surfaces, boundary layer thickness and wall friction coefficient can be determined at the center of the flume floor in all of the stations with Eqs. (4) and (5):

$$
\begin{aligned}
& \frac{\delta}{x}=\frac{0.382}{\operatorname{Re}_{x}^{1 / 5}}, \\
& C_{f}=\frac{2 \tau_{b}}{\rho U^{2}},
\end{aligned}
$$

where $\delta$ is the boundary layer thickness, $x$ is the station distance from the beginning edge of the flume, $\operatorname{Re}_{x}$ is the length Reynolds number, $\tau_{b}$ is shear stress, $\rho$ is the fluid density, $U$ is the velocity, and $C_{f}$ is the wall friction coefficient. The value of the shear stresses at the channel centre for all 11 stations was then determined.

The values of static and total pressure differences in various aspect ratios of $B / H$ were measured and reported by a pressure transducer apparatus with a capacity of 200 mill bar and a measuring frequency of $50 \mathrm{~Hz}$. In order to create a uniform flow condition and match the hydraulic gradient with the flume bed slope, a weir at the end of the flume was installed.

By changing the flow rate resulting in different aspect ratio values, the static and total pressure differences were measured in each of the Preston tubes. Then, by using the Patel and Bechert equations, the shear stresses in all 11 stations were measured. By comparing relative differences of shear stress values resulting from both methods of Patel and Bechert, the possibility of suggesting an optimal Preston tube diameter in determining the local shear stress was provided. After determining an optimal Preston tube diameter, the shear stress in the bed and wall of the channel was calculated. For this purpose, the Preston tube was transferred in the vicinity of wall and bed using a two-dimensional movable seat. In addition, the values of static and total pressure differences in each aspect ratio were measured and reported.

\section{Results and discussion}

\subsection{Sensitivity analysis}

All measurements were performed in the range of 11.06 to 102.38 liter per second flow rate. Flow rate variations led to observable changes in water depth ranging from $4.3 \mathrm{~cm}$ to $21 \mathrm{~cm}$ and the aspect ratios of 2.86 to 13.95 . As previously noted, from the aspect of the sensitivity analysis of the Preston tube diameter in determining the shear stress, four Preston tubes with external diameters of $3.2,3.9,4.7$, and $6.3 \mathrm{~mm}$ were used. For each aspect ratio, the difference in values of Preston-static tube and total pressure using four different diameters was marked, measured, and recorded in all eleven stations. Then, by using the Patel and Bechert calibration equations, local shear stress was calculated and results were compared. Reynolds numbers in all trials were changed in the range of $6.4 \times 10^{4}$ to $39.87 \times 10^{4}$, indicating that this research was performed under the turbulent flow condition. In order to determine the hydraulic gradient, depth and velocity values were measured in consecutive sections 
Table 1. Summary of experimental results.

\begin{tabular}{ccccccccc}
\hline Number & $\boldsymbol{H}(\mathbf{m})$ & $\boldsymbol{B} / \boldsymbol{H}$ & $\boldsymbol{Q}(\mathbf{L} / \mathbf{s})$ & $\boldsymbol{V}(\mathbf{m} / \mathbf{s})$ & $\mathbf{F r}$ & $\mathbf{R e} \times \mathbf{1 0}^{4}$ & $\mathbf{R e}^{*}$ & $\gamma \boldsymbol{H} \boldsymbol{S}$ \\
\hline H-1 & 0.21 & 2.86 & 102.38 & 0.813 & 0.566 & 39.87 & 0.609 & 2.162 \\
H-2 & 0.133 & 4.51 & 53.73 & 0.673 & 0.59 & 24.65 & 0.505 & 1.369 \\
H-3 & 0.113 & 5.31 & 43.6 & 0.643 & 0.611 & 20.98 & 0.482 & 1.163 \\
H-4 & 0.097 & 6.19 & 34.39 & 0.591 & 0.606 & 17.21 & 0.443 & 0.998 \\
H-5 & 0.084 & 7.14 & 28.63 & 0.568 & 0.626 & 14.81 & 0.426 & 0.864 \\
H-6 & 0.076 & 7.89 & 24.42 & 0.536 & 0.621 & 12.9 & 0.402 & 0.782 \\
H-7 & 0.067 & 8.96 & 20.71 & 0.515 & 0.636 & 11.21 & 0.386 & 0.689 \\
H-8 & 0.056 & 10.71 & 16.17 & 0.481 & 0.65 & 9.02 & 0.361 & 0.576 \\
H-9 & 0.049 & 12.24 & 12.54 & 0.427 & 0.615 & 7.13 & 0.32 & 0.504 \\
H-10 & 0.043 & 13.95 & 11.06 & 0.429 & 0.66 & 6.4 & 0.322 & 0.442 \\
\hline
\end{tabular}

* The shear Reynolds number.

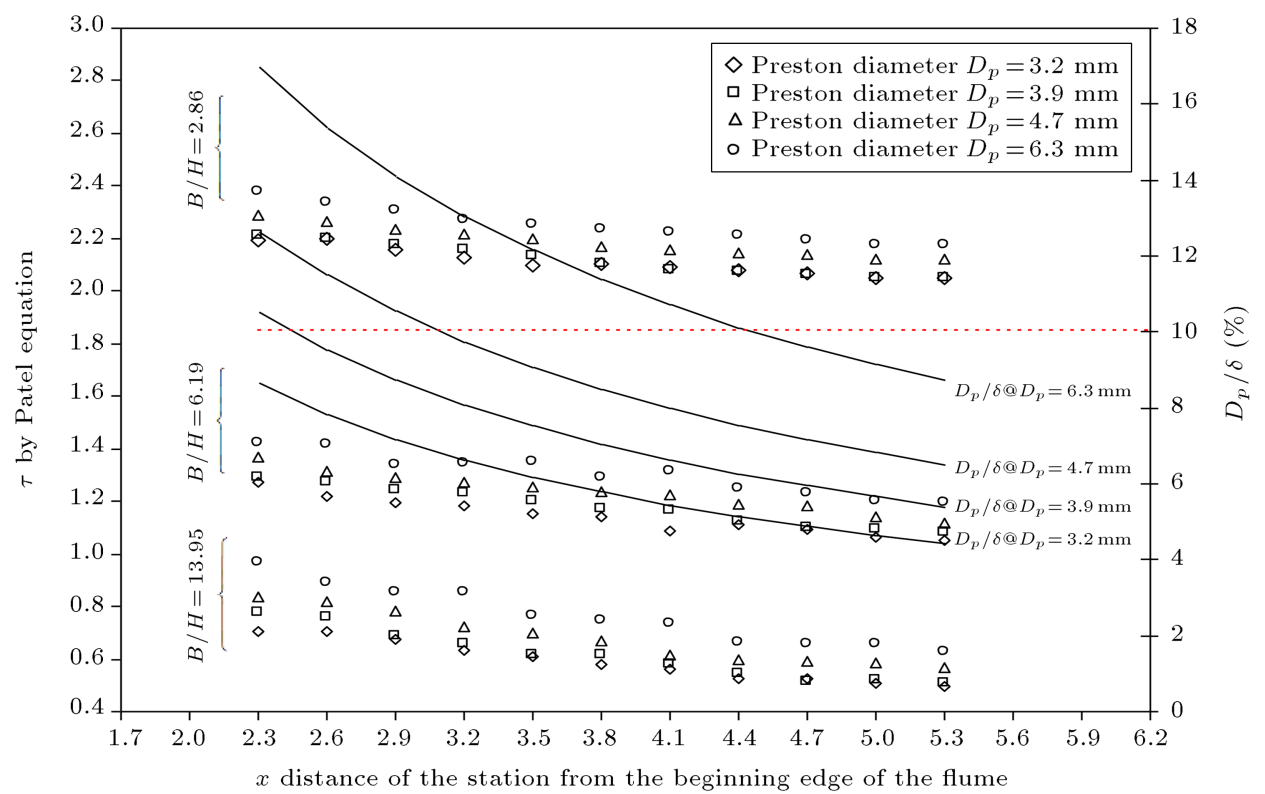

Figure 3. Comparison of the ratio of the Preston tube diameter on boundary layer thickness and longitude distribution of shear stress derived from Patel calibration equation.

with a one-meter distance. A Pitot tube was used for measuring the velocity. After determining the hydraulic gradient between the sections and drawing its profiles, the average hydraulic gradient was then calculated. An average hydraulic gradient of $1.2 \times 10^{-3}$ was estimated in all experiments. A summary of the scenarios examined in this study is displayed in Table 1. To meet the recommended conditions by Preston [25] on the ratio of pipe diameter $D_{p}$ to the thickness of boundary layer $\delta$, the relative amounts of this ratio were calculated in each of the eleven measuring stations by changing the Preston tube diameter and aspect ratio $B / H$. An example of the surveys in aspect ratios of 2.86, 6.19, and 13.95 is provided in Figure 3. Survey results in all aspect ratios show that the three last measurement stations have the Preston (1954) proper conditions about the installation of Preston tube diameter in ten percent of the thickness of the boundary layer for all four-pipe diameters. Therefore, the average shear stresses of the last three stations were selected as the basis for the comparison of the shear stresses calculated by Patel and Bechert calibration equations. Figure 4 shows the Preston tubes number $\left(D_{p} u_{*} / v\right)$ variations trend versus the aspect ratio. The difference in the percentage of the shear stress calculated by the Patel and Bechert equations and that of the aspect ratio for the use of all four Preston tube diameters is shown in this figure. Apparently, the use of $3.9 \mathrm{~mm}$ diameter represents the smallest difference between the results of the Patel and Bechert calibration equations. Using Eqs. (4) and (5), the wall friction coefficient values versus normalized pressure difference 


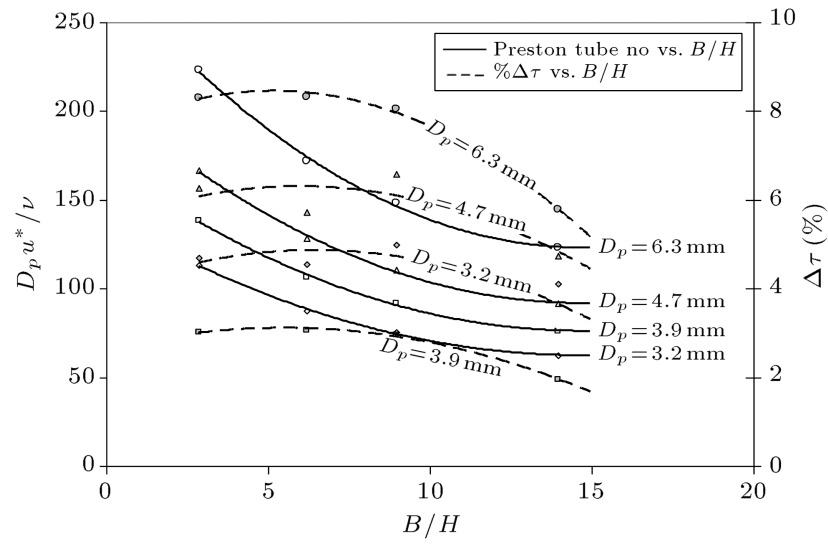

Figure 4. Comparison of the difference in the percentage of shear stress resulting from Bechert and Patel $(\% \Delta \tau)$ versus that of aspect ratio, as well as left coordinate variation trend of the Preston tube number versus aspect ratio.

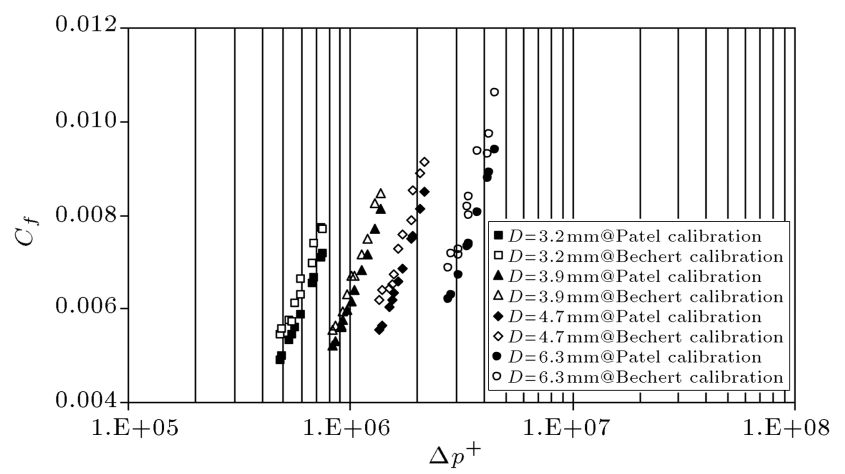

Figure 5. Wall friction coefficient variation versus normalized pressure difference in the aspect ratio of 13.95 .

values in all aspect ratios were calculated by the Patel and Bechert calibration equations. Figure 5 shows an example of the wall friction coefficient variations versus the normalized pressure difference in the aspect ratio of 13.95. Surveying the results of wall friction coefficients also indicates that the use of $3.9 \mathrm{~mm}$ diameter represents the smallest difference between the results of Bechert and Patel calibration equations for the average shear stress. The results presented in Figure 5 show that, for the use of all different Preston tube diameters, shear stress values obtained through the Bechert calibration equation are larger than those of the Patel calibration equation.

\subsection{Results of the transverse shear-stress distribution}

By determining the transverse shear-stress distribution in the vicinity of the rectangular channel bed and wall, Preston tubes were moved with a two-dimensional movable seat adjacent to the wall and bed. The interval of these locations changing in the vicinity of the bed and wall was between 5 and $10 \mathrm{~mm}$. The bed and wall local shear stress was measured, as shown in Table 1 , for all of the $B / H$ aspect ratios using differential pressure meter of the Preston tube and the Patel calibration curve. Schematic of local bed and wall shear stress distribution is shown in Figure 6. Figures 7 to 12 show the transverse distribution of local shear stress in bed and wall for aspect ratios of $2.86,6.19$, and 13.95 .

To facilitate the comprehension of these results, attempts have been made to present the relative parameters in dimensionless forms as $\tau_{b} / \bar{\tau}_{b}$ and $\tau_{w} / \bar{\tau}_{w}$, where $\tau_{b}$ is the local shear stress in the bed and wall, and $\bar{\tau}_{b}$ and $\bar{\tau}_{w}$ are average shear stresses in the bed and wall, respectively. According to laboratory observations, $\tau_{b} / \bar{\tau}_{b}$ and $\tau_{w} / \bar{\tau}_{w}$ have the maximum value that occurs in aspect ratios of 2.7 and 1, respectively.

Non-linear regression equations were used in order to achieve the governing equations of the transverse distribution of local shear stress in the wall and bed in smooth rectangular channels. For this purpose, the SPSS software was used. Eqs. (6) and (7) represent the transverse distribution of shear stress in the bed and wall, which became dimensionless by the total shear stress.

$$
\begin{aligned}
\frac{\tau_{b}}{\gamma H S}= & \left(1-1.1082(B / H)^{-1.3709}\right) \\
& \times \exp \left(0.85-0.5922(b / B)^{-0.2858}\right) \\
\frac{\tau_{w}}{\gamma H S}= & \left(1-1.9255(B / H)^{-2.4997}\right) \\
& \times \exp \left(-0.3166-0.0187(Z / H)^{-0.8415}\right)
\end{aligned}
$$
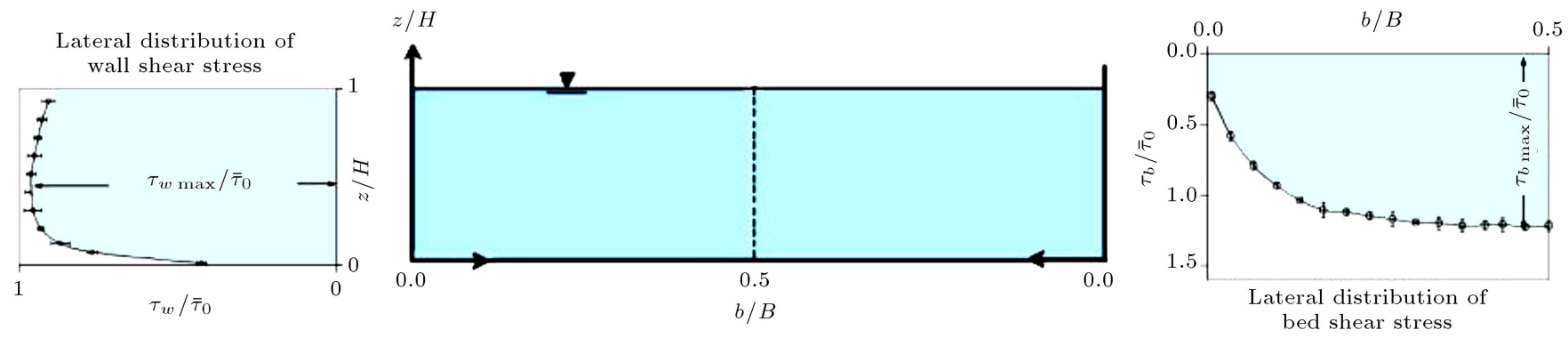

Figure 6. Schematics of local coordinates of shear stress distribution in wall and bed of the rectangular channel. 


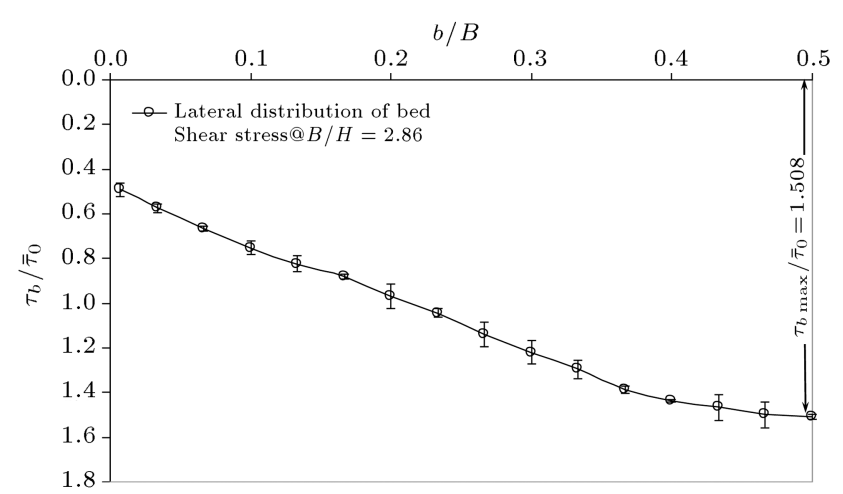

Figure 7. Distribution of shear stress in channel bed at $B / H=2.86$.

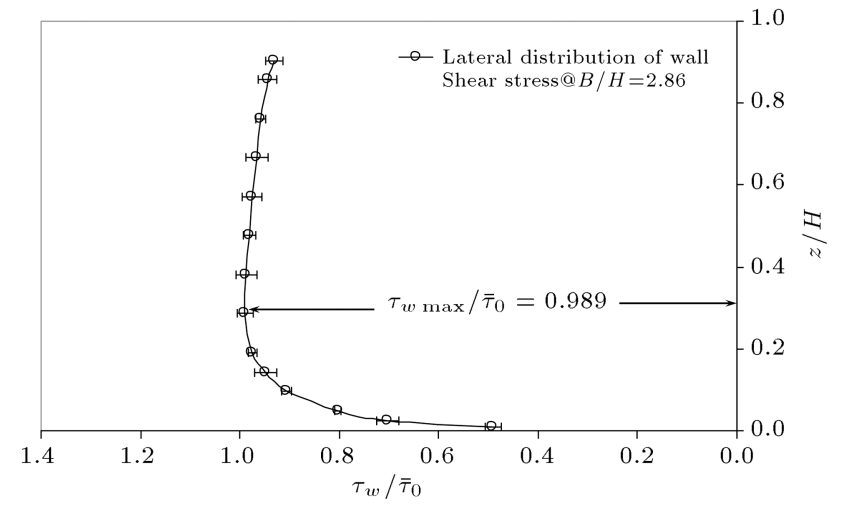

Figure 8. Channel wall shear stress distribution at $B / H=2.86$.

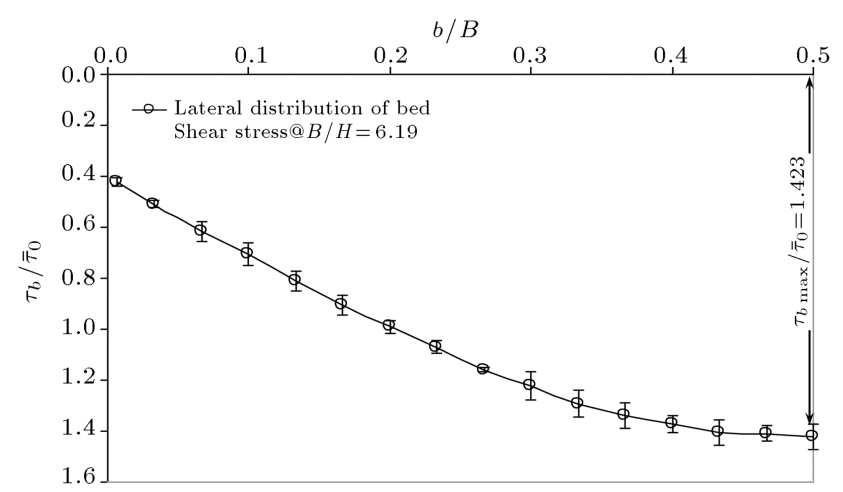

Figure 9. Distribution of shear stress in channel bed at $B / H=6.19$.

In order to verify the accuracy of the results of Eqs. (6) and (7), Figures 13 and 14 show the theoretically calculated results of $\tau_{b} / \gamma H S$ against observed $\tau_{b} / \gamma H S$ data and, also, show the theoretically calculated results of $\tau_{w} / \gamma H S$ against observed $\tau_{w} / \gamma H S$ data. Table 2

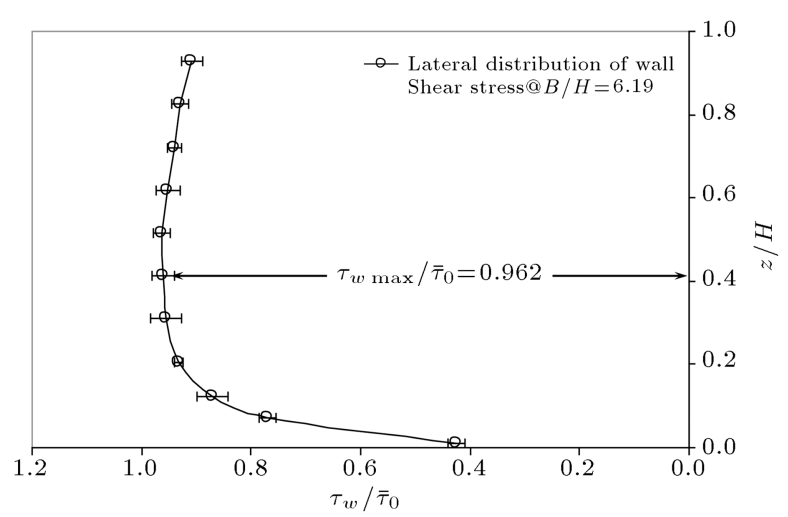

Figure 10. Channel wall shear stress distribution at $B / H=6.19$.

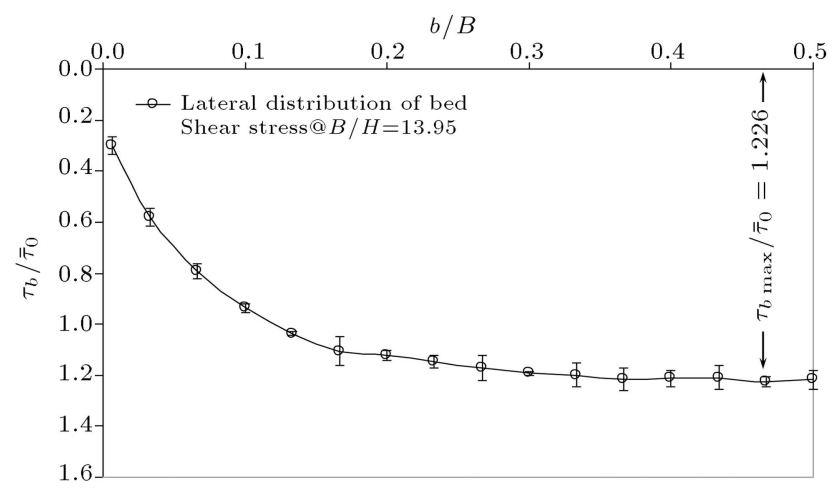

Figure 11. Distribution of shear stress in channel bed at $B / H=13.95$.

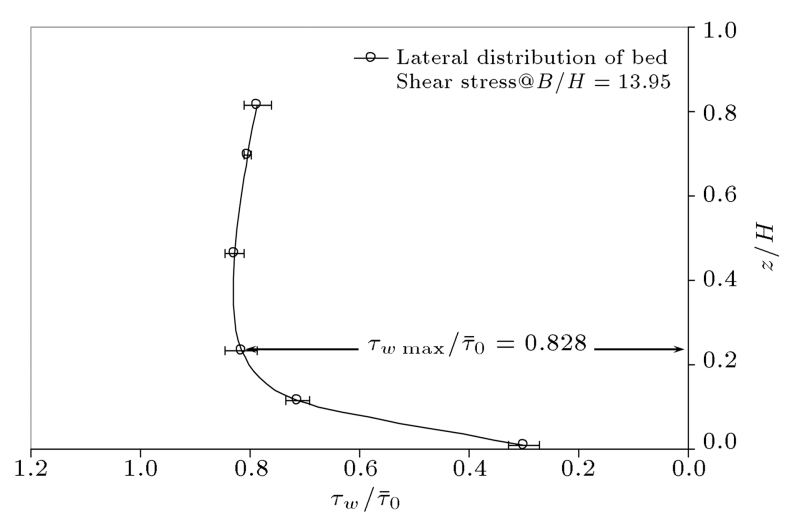

Figure 12. Channel wall shear stress distribution at $B / H=13.95$.

shows the statistical analysis of the predicted results by Eqs. (6) and (7) versus laboratory observations. In order to obtain a better understanding of the process of the variations in Eqs. (6) and (7) versus the aspect

Table 2. Error functions resulting from Eqs. (6) and (7) versus experimental observations.

\begin{tabular}{cccccccc}
\hline Equation & ME & MPE & MAE & RMSE & SEE & CRM & $\boldsymbol{R}^{\mathbf{2}}$ \\
\hline$\tau_{b} / \gamma H S$ & 0.159 & -0.149 & 0.0066 & 0.0247 & 0.0688 & 0.0189 & 0.9088 \\
$\tau_{w} / \gamma H S$ & 0.0448 & 0.7554 & 0.0029 & 0.0094 & 0.0304 & 0.0017 & 0.9707 \\
\hline
\end{tabular}




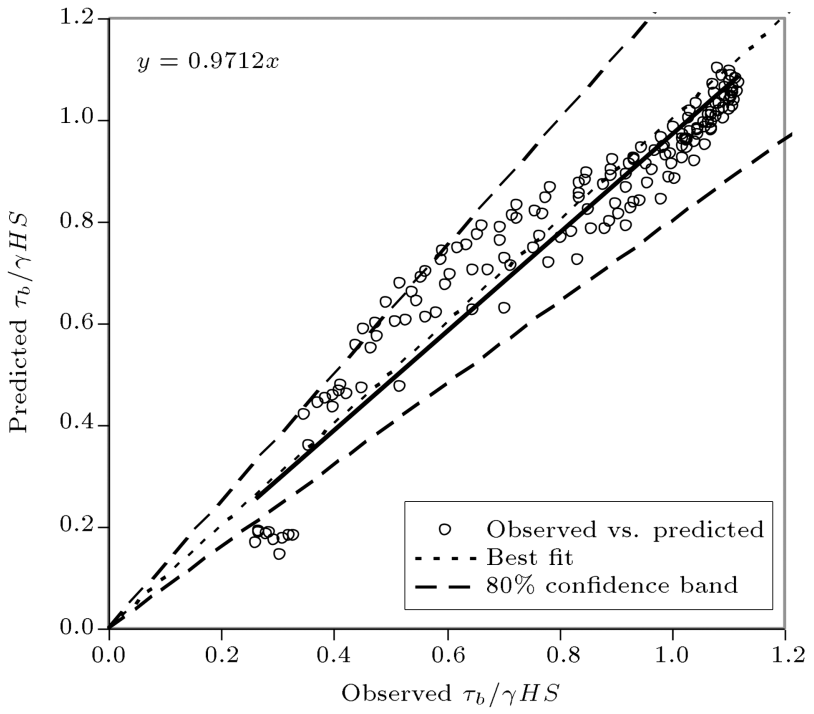

Figure 13. Fitting predicted results of Eq. (6) with experimental results for estimating $\tau_{b} / \gamma H S$.

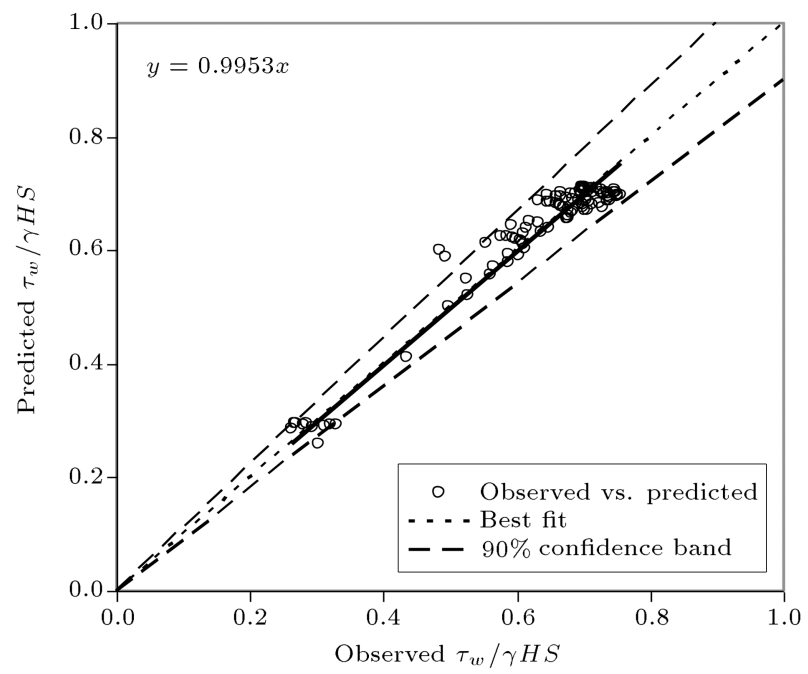

Figure 14. Fitting predicted results of Eq. (7) with experimental results for estimating $\tau_{w} / \gamma H S$.

ratio and location in cross-section, Figures 15 and 16 show the three-dimensional space procedures of the aforementioned equations.

The procedure depicted in Figure 15 indicates that $B / H$ aspect ratio is effective in dimensionless bed shear stress distribution $\tau_{b} / \gamma H S$. A similar analysis can be seen in Figure 16, which seemingly has only minor effect on the wall shear stress distribution $\tau_{w} / \gamma H S$ in rectangular open channels.

In order to compare the results of this study with previous researches, laboratory results of Knight et al. [26], Knight and Hamed [27], Myers and Elsawy [28], and Cokljat and Younis [29] have been used. Figure 17 shows the results predicted by Eq. (6) versus those of previous research in the aspect ratio range of 3.91 to 4.74. In Figure 18, the prediction results of Eq. (7)

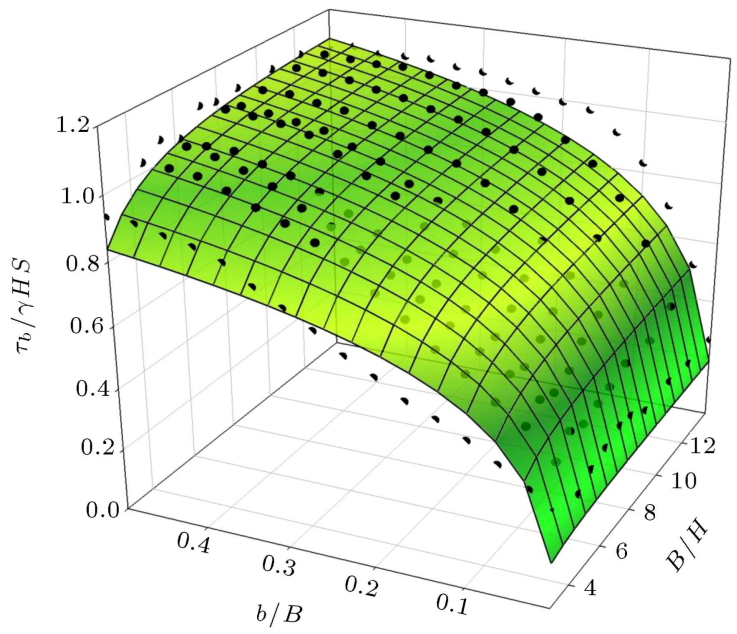

Figure 15. Local variations $(b / B)$ of relative bed shear stress $\tau_{b} / \gamma H S$ versus aspect ratio $(B / H)$.

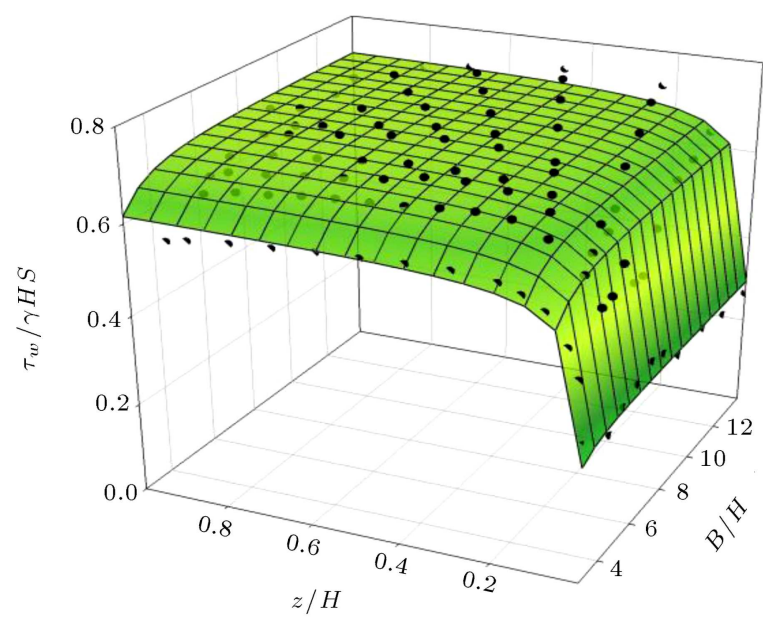

Figure 16. Local variations $(z / H)$ of relative wall shear stress $\tau_{w} / \gamma H S$ versus aspect ratio $(B / H)$.

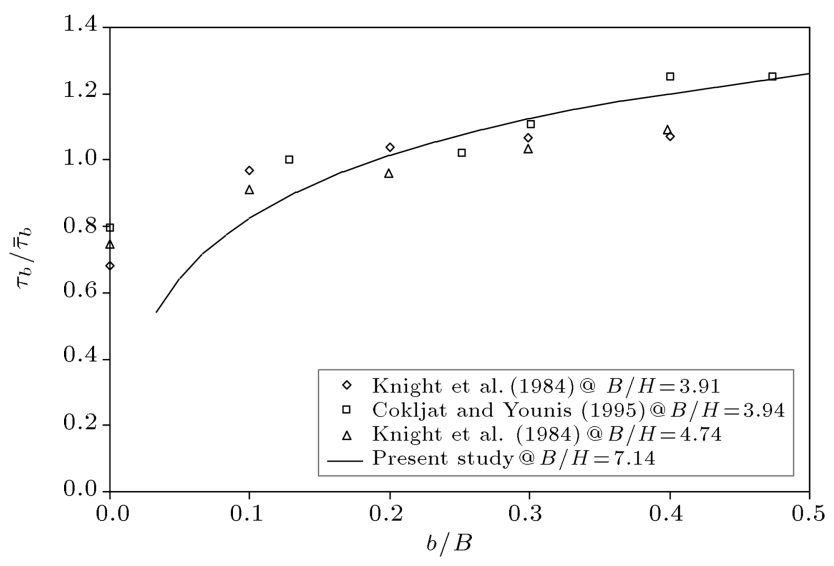

Figure 17. Shear stress distribution in the bed of rectangular channels in different studies.

and the results of the laboratory research of Knight et al. [26], Knight and Hamed [27], and Meyers and Elsawy [28] with $B / H$ aspect ratio in the range of 


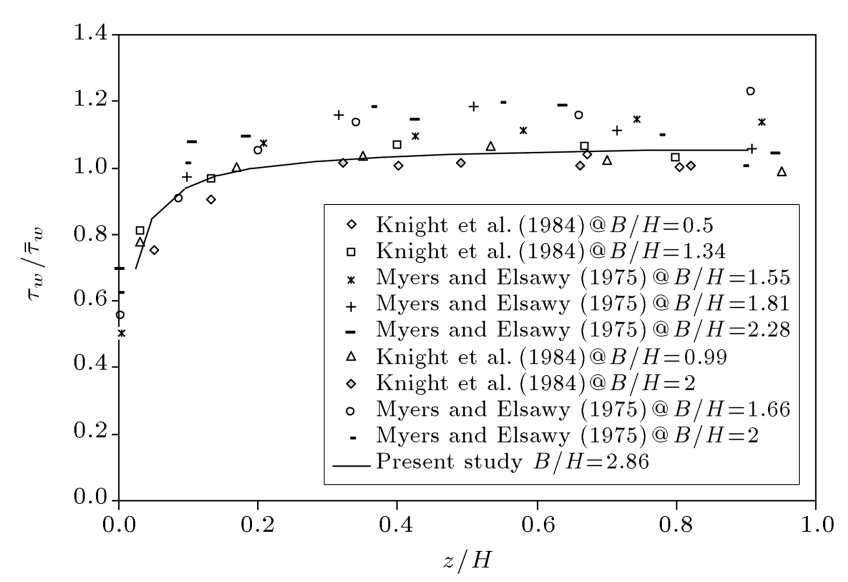

Figure 18. Shear stress distribution in the wall of rectangular channels in different studies.

1.5 to 8 are displayed. According to the predicted results versus the experimental results of the other researchers, predictions of Eqs. (6) and (7) are properly consistent with previous experimental researches. The relative independence of wall shear stress $\tau_{w} / \gamma H S$ in this comparison is remarkable and striking.

\section{Discussion}

In this section, the analysis of the results is carried out in order to design open channels. Open channel design requires knowledge of the shear stress and knowing how to distribute it in the bed and channel wall. In Figure 19, a variation in the maximum shear stress (derived from laboratory observations of this study) on the bed and wall of rectangular channels is displayed versus the aspect ratio. By expanding the application of the results in different conditions, the maximum observed shear stress in the bed and wall became dimensionless using the average stress. Since observations of this study do not include the aspect ratios smaller than 2.85, the present experimental observations and those of Kartha and Leutheusser [3]

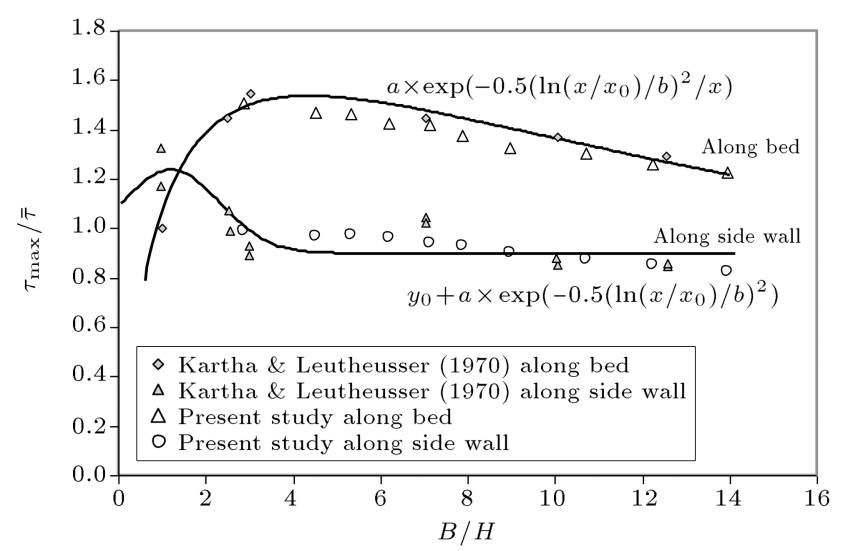

Figure 19. Variations of $\tau_{b \max } / \bar{\tau}_{b}$ and $\tau_{w \max } / \bar{\tau}_{w}$ versus $B / H$. are displayed in this figure. All the fitted curves from laboratory observations on the bed and wall can be considered as a realistic criterion and a benchmark to be used to design open channels. The results showed that bed shear stress $\tau_{\max } / \bar{\tau}$ for the aspect ratio of 2.7 would increase the shear stress to 1.55 times the average amount. Results also show that in the aspect ratio of 1 , close to the wall, $\tau_{\max } / \bar{\tau}$ will increase 1.31 times the average shear stress. Since the maximum values of shear stress $\tau_{\max } / \bar{\tau}$ in the vicinity of the wall and the bed are identified in aspect ratios near 2 , it can be concluded that the best hydraulic conditions could be a critical requirement for open channel design using shear stress, which should be considered. In a developed aspect ratio close to 2 of the wall and bed, shear stresses are in a critical state. Hence, they both should be designed as a criterion to be considered. On the other hand, for aspect ratios greater than 2, the amounts of shear stress in the vicinity of the wall tend to be 1 , suggesting that the shear stress should be considered as a standard in channel designing.

\section{Conclusions}

This study was performed to determine the optimal diameter of the Preston tube and aimed to investigate the distribution of the wall and the bed local shear stress in smooth rectangular channels. Preston tubes with external diameters of $3.2,3.9,4.7$, and $6.3 \mathrm{~mm}$ were used. Analysis of the uniform conditions variations in aspect ratios of 2.86 to 13.95 was carried out. The results showed that the application of a pipe with an external diameter of $3.9 \mathrm{~mm}$ presented the minimum difference in the average shear stress derived from the Patel and Bechert calibration equations. For steady flow conditions used in this study, different relations were presented to determine the transverse distribution of shear stress in the bed and wall. These relationships are a function of $B / H$ aspect ratio and relative coordinates of the bed cross-section $b / B$ and walls $z / H$.

The results showed that both the wall shear stress and the bed shear stress should be considered as an open channel design criterion when the aspect ratio develops in the neighborhood of 2. Bed shear stress should be considered as a design criterion by the designers for channels with an aspect ratio larger than 3 .

The results showed that the dimensionless shear stress distribution was considerably influenced by the aspect ratio. The transverse distribution of stress in the wall is independent of aspect ratio for that greater than 3. For all examined flow conditions in this study, the maximum shear stress was observed mainly in the middle of the channel. 


\section{Acknowledgments}

The authors of this study thank and acknowledge the Jundi-Shapur University of Technology, Dezful, Iran for laboratory facilities, support, and financing.

\section{References}

1. Olsen, O.J. and Florey Q.L. "Sedimentation studies in open channels: Boundary shear and velocity distribution by the membrane analogy, analytical, and finitedifference methods", Laboratory Report, Sp-34, U.S. Bureau of Reclamation (1952).

2. Ghosh, S.N. and Roy, N. "Boundary shear distribution in open channel flow", Journal of Hydraulic Division, ASCE, 96(4), pp. 967-994 (1970).

3. Kartha, V.C. and Leutheusser, H.J. "Distribution of tractive force in open channels", Journal of the Hydraulics Division, ASCE, 15, pp. 1469-1483 (1970).

4. Knight, D.W. and Patel, H.S. "Boundary shear in smooth rectangular ducts", Journal of Hydraulic Engineering, ASCE, 111(1), pp. 29-47 (1985a).

5. Knight, D.W. and Patel, H.S. "Boundary shear stress distributions in rectangular duct flow", In Proceedings of the 2nd Intl Symposium On Refined Flow Modeling and Turbulence Measurements, Hemisphere, Washington, 122, pp. 1-10 (1985b).

6. Knight, D.W., Yuen, K.W.H., and Al Hamid, A.A.F. "Boundary shear stress distributions in open channel flow", In Physical Mechanisms of Mixing and Transport in the Environment, K. Bevon, P. Chakin and J. Willbank, Eds., J. Wiley, New York, USA, pp. 51-87 (1994).

7. Sutardi, M. and Ching, C.Y. "Effect of tube diameter on Preston tube calibration curves for the measurement of wall shear stress", Experimental Thermal and Fluid Science, 24(3), pp. 93-97 (2001).

8. Bechert, D.W. "Calibration of Preston tube", AIA A Journal, 34(1), pp. 205-206 (1995).

9. Patel, V.C. "Calibration of the Preston tube and limitations on its use in pressure gradients", Journal of Fluid Mechanics, 23, pp. 185-208 (1965).

10. Ardiçlioğlu, M., Seçkin, G., and Yurtal, R. "Shear stress distributions along the cross-section in smooth and rough open channel flows", Kuwait Journal of Science and Engineering, 33(1), pp. 155-168 (2005).

11. Knight, D.W., Omran, M., and Tang, X. "Modeling depth-averaged velocity and boundary shear in trapezoidal channels with secondary flows", Journal of Hydraulic Engineering, 133(1), pp. 39-47 (2007).

12. Lashkar-Ara, B., Fathi-Moghadam, M., ShafaiBajestan, M., and Jael, A. "Boundary shear stress in smooth channels", International Journal of Food, Agriculture \& Environment, 8, pp. 343-347 (2010).

13. Lashkar-Ara, B. and Fathi-Moghadam, M. "Analysis of shear stress in rectangular open channels using force balance method", Journal of Hydraulics, 9(3), pp. 33-44 (2014) (In Persian).
14. Lv, H., Jiang, C., Xiang, Z., Ma, B., Deng, J., and Yuan, W. "Design of a micro floating element shear stress sensor", Flow Measurement and Instrumentation, 30, pp. 66-74 (2013).

15. Devi, K. and Khatua, K.K. "Prediction of depth averaged velocity and boundary shear distribution of a compound channel based on the mixing layer theory", Flow Measurement and Instrumentation, 31(50), pp. 147-157 (2016).

16. Park, J.H., Do Kim, Y., Park, Y.S., Jo, J.A., and Kang, K. "Direct measurement of bottom shear stress under high-velocity flow condition", Flow Measurement and Instrumentation, 30, pp. 121-127 (2016).

17. Shan, Y., Liu, C., Luo, M., and Yang, K. "A simple method for estimating bed shear stress in smooth and vegetated compound channels", Journal of Hydrodynamics, Ser. B, 28(3), pp. 497-505 (2016).

18. Sheikh Khozani, Z. and Bonakdari, H. "Comparison of five different models in predicting the shear stress distribution in straight compound channels", Scientia Iranica, Transaction A: Civil Engineering, 23(6), pp. 2536-2545 (2016).

19. Yang, S.Q. and Lim, S.Y. "Mechanism of energy transportation and turbulent flow in a 3D channel", J. Hydraul. Eng., 123(8), pp. 684-692 (1997).

20. Khodashenas, S.R. and Paquier, A. "A geometrical method for computing the distribution of boundary shear stress across irregular straight open channel", J. Hydraul. Res., 37(3), pp. 381-388 (1999).

21. Sterling, M. and Knight, D.W. "An attempt at using the entropy approach to predict the transverse distribution of boundary shear stress in open channel flow", Stoch. Env. Res. Risk Assess., 16(2), pp. 127-142 (2002).

22. Zarrati, A.R., Jin, Y.C., and Karimpour, S. "Semianalytical model for shear stress distribution in simple and compound open channels", J. Hydraul. Eng., 134(2), pp. 205-215 (2008).

23. Bonakdari, H., Larrarte, F., and Joannis, C. "Study of shear stress in narrow channels: application to sewers", Urban Water, 5(1), pp. 15-20 (2008).

24. Mohammadi, M.A. "On the distribution of velocity in a V-shaped channel", Scientia Iranica, Transactions A: Civil Engineering, 16(1), pp. 78-86 (2009).

25. Preston, J.H. "The determination of turbulent skin friction by means of pitot tubes", Journal of the Royal Aeronautical Society, 58(518), pp. 109-121 (1954).

26. Knight, D.W., Demetriou, J.D., and Hamed, M.E. "Boundary shear in smooth rectangular channels", Journal Hydraulics Engineering, ASCE, 110(4), pp. 405-422 (1984).

27. Knight, D.W. and Hamed, M.E. "Boundary shear in symmetrical compound channels", Journal of Hydraulic Engineering, ASCE, 110(10), pp. 1412-1430 (1984). 
28. Myers, R.C. and Elsawy, E.M. "Boundary shear in channel with flood plain", Journal of Hydraulic Division, ASCE, 101(7), pp. 933-946 (1975).

29. Cokljat, D. and Younis B.A. "Second-order closure study of open-channel flows", Journal of Hydraulic Engineering, ASCE, 121(2), pp. 94-107 (1995).

\section{Biographies}

Babak Lashkar-Ara is an Associate Professor in Civil Engineering Department, Jundi-Shapur University of Technology, Dezful, Iran. He received his $\mathrm{PhD}$ in
Hydraulic Structures from Shahid Chamran University of Ahwaz, Ahwaz, Iran, in 2009. He has authored and co-authors over 47 papers in reputed national/ international journals and over 65 papers in Iranian national/ international conference.

Masumeh Fatahi has completed her MSc degree in Civil Engineering from the Jundi-Shapur University of Technology, Dezful, Iran, in 2016. She is now PhD student in Civil Engineering in University of Qom, Qom, Iran. She has authored 3 papers in Iranian national journals. 